\title{
Mercury Disposition in Suckling Rats: Comparative Assessment Following Parenteral Exposure to Thiomersal and Mercuric Chloride
}

\author{
Maja Blanuša, Tatjana Orct, Maja Vihnanek Lazarus, Ankica Sekovanić, and Martina Piasek \\ Analytical Toxicology and Mineral Metabolism Unit, Institute for Medical Research and Occupational Health, Ksaverska cesta 2, \\ P.O. Box 291, HR-10001 Zagreb, Croatia \\ Correspondence should be addressed to Tatjana Orct, torct@imi.hr \\ Received 5 April 2012; Accepted 25 May 2012 \\ Academic Editor: João B. T. Rocha \\ Copyright () 2012 Maja Blanuša et al. This is an open access article distributed under the Creative Commons Attribution License, \\ which permits unrestricted use, distribution, and reproduction in any medium, provided the original work is properly cited.
}

Due to the facts that thiomersal-containing vaccine is still in use in many developing countries, and all forms of mercury have recognised neurotoxic, nephrotoxic, and other toxic effects, studies on disposition of ethylmercury and other mercury forms are still justified, especially at young age. Our investigation aimed at comparing mercury distribution and rate of excretion in the early period of life following exposure to either thiomersal (TM) or mercuric chloride $\left(\mathrm{HgCl}_{2}\right)$ in suckling rats. Three experimental groups were studied: control, $\mathrm{TM}$, and $\mathrm{HgCl}_{2}$, with 12 to 18 pups in each. Both forms of mercury were administered subcutaneously in equimolar quantities $(0.81 \mu \mathrm{mol} / \mathrm{kg}$ b.w.) three times during the suckling period (on the days of birth 7,9 , and 11) to mimic the vaccination regimen in infants. After the last administration of $\mathrm{TM}$ or $\mathrm{HgCl}_{2}$, total mercury retention and excretion was assessed during following six days. In TM-exposed group mercury retention was higher in the brain, enteral excretion was similar, and urinary excretion was much lower compared to $\mathrm{HgCl}_{2}$-exposed sucklings. More research is still needed to elucidate all aspects of toxicokinetics and most harmful neurotoxic potential of various forms of mercury, especially in the earliest period of life.

\section{Introduction}

Mercury is a pervasive environmental contaminant with proven toxic properties in mammals. Major risks recognized due to mercury exposure are dietary methylmercury exposure from fish and seafood, elemental mercury vapour from amalgam in tooth "silver fillings," and thiomersal-contained ethylmercury in vaccines [1-3]. Thiomersal (thimerosal, merthiolate) has been banned in the United States and Canada since 1999 and in the European Union since 2001 from vaccines recommended for children below seven years [4-6].

The molecule of thiomersal is sodium ethylmercurythiosalycilate that dissociates to ethylmercury and thiosalicylate [7]. Ethylmercury is acting as a preservative against bacterial and fungal contamination of the vaccines that are repeatedly given to infants (Diphtheria-Tetanus-acellularPertussis vaccine, 3 to 7 times) up to 6 months of age. A potential threat of neurodevelopmental toxic effect of mercury lies in the fact that the exposure occurs in the most vulnerable period of life, when the brain is developing and growing [8]. Organic forms of mercury are more easily absorbed when ingested and are less readily eliminated from the body than its inorganic forms [1].

By now considerable amount of evidence has been collected to prove that doses of thiomersal in human vaccines do not pose harm, except for the risk of local hypersensitivity reactions [9-19]. In a recent overview Dórea [20] integrated experimental neurotoxicity studies of low-dose thiomersal in vaccines and concluded that doses relevant to thiomersalcontaining vaccines exposure possess the potential to affect human neurodevelopment. A recently published experimental study in thiomersal-exposed infant rats reopens the debate on thiomersal-induced neurotoxic threat showing perturbations in the balance between excitatory and inhibitory amino acids in the brain, shifting it towards excessive neuroexcitation that may lead to neurodevelopmental disorders [21]. 
Recent large European cohort studies, such as the one conducted in Spain, show that increased perinatal mercury exposure is mostly related to maternal fish consumption, which means methylmercury intake [3]. However, the fact remains that during the first six months of life some infants might be exposed to cumulative levels of mercury that could exceed United States Environmental Protection Agency reference doses $(5.8 \mu \mathrm{g} / \mathrm{L}$ of methylmercury or $6.4 \mu \mathrm{g} / \mathrm{L}$ of total mercury). The latter has been taken into account when setting up the recommendation for reduction of total mercury exposure and elimination of mercury use whenever possible [2].

Due to the present widespread use of thiomersal-containing vaccine in many developing countries and the fact that mercury is well recognised toxic metal, studies on disposition of ethylmercury and other mercury forms in mammalian organism including humans are still justified since numerous controversies still exist. Due to bioethical obstacles associated with such studies in infants, more studies on experimental animals are needed to quantify distribution and rate of mercury excretion after thiomersal exposure. We conducted our investigation to obtain a more detailed insight into distribution and rate of excretion in rodents in early period of life. The scope of our investigation was to assess organ retention and excretion of mercury following exposure to thiomersal compared to inorganic mercury (mercuric chloride) in suckling rats. We utilized the data and experience gained through foregoing experimental work on inorganic mercury that was conducted in our Unit by research team of Kostial et al. [22-25]. Past research confirmed that under same exposure conditions higher mercury retention is found in the gut and the brain of young compared to adult experimental animals. In our present investigation, we administered both forms of mercury subcutaneously, three times during suckling period, to mimic the type of administration (parenteral, intramuscular application) and usual vaccination regimen in infants. After the last thiomersal administration, mercury retention, and excretion was followed up during six consecutive days. Special attention was paid to the comparison of excretion rate (measured as total mercury) in thiomersal versus inorganic mercuryexposed study groups.

\section{Material and Methods}

2.1. Experimental Animals. Experimental rats (Wistar strain reared in the Laboratory Animal Unit of the Institute for Medical Research and Occupational Health in Zagreb, Croatia) were supplied with feed for small laboratory animals (Muccedola, Milano, Italy) and tap water ad libitum. Animal facility was kept under constant indoor conditions (20$22^{\circ} \mathrm{C}$, constant humidity of $40 \%$, and $12 \mathrm{~h} \mathrm{light/dark} \mathrm{cycles).}$ Animal cages were provided by sterilised pine shaving beddings. Two weeks after mating (in ratio male:female $1: 3$ over a week), pregnant rats were placed into small individual polycarbonate cages $(20.7 \times 26.5 \times 14.0 \mathrm{~cm}$, Ehret, Germany $)$ where they gave birth and reared the litters. Six mother rats with the litters that delivered on the same day were designated for the experiment. The litters were normalized to eight male pups per litter one day after birth. Pups' body weights were recorded every morning throughout the experiment. All procedures with animals were carried out in accordance with national Law on the Protection of Animal Welfare. The experimental protocol was approved by the Institute's Bioethical Committee and was conducted within the framework of the research project granted by the Croatian Ministry of Science, Education and Sports. The implementation of the protocol was officially permitted by the Veterinary Administration of the Croatian Ministry of Agriculture, Forestry and Water Management.

2.2. Experimental Design. The pups were assigned into three experimental groups: Control, Thiomersal, and $\mathrm{HgCl}_{2}$ with two to three pups per group within each litter, with total number of pups per group 12,18, and 18. The experiment started at pups' age of seven days by subcutaneous injection of deionised water, thiomersal (ethylmercurythiosalicilic acid sodium salt, SERVA Electrophoresis, Germany), or mercuric chloride $\left(\mathrm{HgCl}_{2}\right.$ p.a., Kemika, Croatia), depending on the assignment to the experimental group. The dose of administered mercury in both forms was equimolar, that is, $0.81 \mu \mathrm{mol} / \mathrm{kg}$ b.w. and was given in the volume of $0.05 \mathrm{~mL}$. Compounds were dissolved in deionised water and freshly prepared each time before injection. The dose of mercury used in the experiment was calculated to be $10 \%$ of $\mathrm{LD}_{50}$ dose based on a previous finding for mercuric chloride in suckling rats provided by our Unit. Subcutaneous administration of both mercury forms was repeated three times; first time on the day of birth 7 (as described above), second time on day 9 , and third time on the day of birth 11 . The morning after the last parenteral exposure of either mercury form, from day of birth 12 through 17, during six consecutive days, we euthanized all pups from one litter of each experimental group after intraperitoneal administration of the combination of anaesthetics Narketan plus Xylapan (Vetoquinol AG, Switzerland) in doses 0.8 plus $0.6 \mathrm{~mL} / \mathrm{kg}$ b.w. We then sampled the blood, selected organs, urine, and gut with its content for mercury analysis. Blood was collected from the heart in heparinised syringes. Urine was collected from the urinary bladder with a syringe immediately after opening the abdominal cavity. The brain, kidneys, liver, and entire small and large intestine were dissected after exsanguination from the abdominal aorta.

2.3. Analytical Procedure. Wet (fresh) weights of samples were recorded, and the samples were frozen at $-20^{\circ} \mathrm{C}$ before analysis. Blood and urine samples were analysed directly without digestion. Frozen organ samples were digested, and total mercury analysed as described earlier [26, 27]. The results of mercury mass fraction in organs were expressed as micrograms or nanograms per gram of wet tissue weight $(\mu \mathrm{g}$ or $\mathrm{ng} / \mathrm{g}$ w.w.) and concentrations of mercury in blood and urine as micrograms per litter $(\mu \mathrm{g} / \mathrm{L})$.

2.4. Statistical Analysis. The hypothesis of normal distribution of data was tested by Shapiro-Wilk's W test. The results are presented as arithmetic means and standard deviations 
or median with a range of minimum and maximum values. Differences between parameters in the rats given two different forms of mercury were analysed at each sampling point by Student's $t$-test. Correlations (Pearson's correlation coefficient) between two forms of mercury in different tissues obtained during the entire six-day collection period were calculated. We used Statistica Programme (StatSoft, Inc., version 9.0) for the statistical analysis. The level of $P<0.05$ was considered significant.

\section{Results}

During the period of exposure to mercury, between day of birth 7 and 12, body weight gain was $2.2 \pm 0.4 \mathrm{~g}$ a day. No differences between experimental groups were found in either body weight gain or organ weights at the end of experiment. Three doses of $0.81 \mu \mathrm{mol} / \mathrm{kg}$ of either mercury form caused no signs of general toxicity. The timing of injection of two forms of mercury was a compromise of imitation of infant vaccination regimen and age when pups are suckling, and not yet reaching for solid feed on the cage. Subcutaneous injection was chosen as a mode of parenteral mercury administration instead of intramuscular injection in growing tiny muscle mass in suckling rats. Total mercury fraction in all analysed tissues of the control pups $(N=12$; 2 pups in each litter) was more than 1000 times lower than values found in the exposed groups. Therefore, we pooled the values of control pups and presented them separately in Table 1, and only the values of two exposed groups were compared by statistical evaluation.

The concentrations in whole blood and urine and mass fractions of mercury in the selected organs of two mercury-exposed groups are presented graphically to show the differences and daily course during six-day collection of samples (Figure 1). In all sampling points, concentrations and mass fractions of total mercury in urine and kidney in $\mathrm{HgCl}_{2}$-exposed group were significantly higher than in TM-exposed group. In the liver and in both small and large intestine, total mercury values were lower, although not always statistically significant. However, total mercury in TM-exposed group was significantly higher both in blood and in brain than in $\mathrm{HgCl}_{2}$-exposed group. During six-day period of sampling, only whole blood showed a decline with time in both mercury-exposed groups (Figure 1).

In the urine, the excretion decreased within six days only in the inorganic mercury exposed group. To find out the similarity of mercury behaviour during six-day sampling period in two experimental groups, correlation between organic and inorganic mercury given to animals was tested in each analyzed organ, whole blood and urine. Statistically significant correlations were found only in whole blood and large intestine (Table 2).

\section{Discussion}

We investigated disposition of two different forms of mercury other than methylmercuy during the critical period of brain maturation process, which occurs in rats during early postnatal period up to age of 3-4 weeks after birth [8]. Our
TABLe 1: Total mercury in whole blood, urine, liver, kidneys, small intestine, large intestine, and brain of the control pups.

\begin{tabular}{lcc}
\hline & Median & Range (min.-max. value) \\
\hline Whole blood $(\mu \mathrm{g} / \mathrm{L})$ & 0.32 & $0.24-0.51$ \\
Urine $(\mu \mathrm{g} / \mathrm{L})$ & 0.19 & $0.1-0.74$ \\
Liver $(\mathrm{ng} / \mathrm{g})$ & 3.56 & $2.97-4.51$ \\
Kidneys $(\mathrm{ng} / \mathrm{g})$ & 10.1 & $6.04-12.37$ \\
Small intestine $(\mathrm{ng} / \mathrm{g})$ & 7.58 & $5.77-9.74$ \\
Large intestine $(\mathrm{ng} / \mathrm{g})$ & 14.2 & $10.26-15.43$ \\
Brain $(\mathrm{ng} / \mathrm{g})$ & 2.24 & $1.82-2.63$ \\
\hline
\end{tabular}

Total number of animals in the control group was 12, that is, 2 pups in each litter of the six litters in total.

results show that mercury levels decreased in blood and urine in a time-dependent manner while mercury mass fractions in all selected organs remained relatively constant during six days following the parenteral exposure. The later finding indicates slow mercury elimination from internal organs. Other authors described similar findings obtained under different experimental conditions following administration of different forms of mercury to neonatal mice or infant monkeys. In mice, after receiving a single intramuscular injection of methylmercury or thiomersal (ethylmercury), mercury levels decreased after seven days in the blood and were unchanged in the brain [28]. Infant monkeys were measured three times after exposure to either methylmercury or thiomersal. The calculated washout $\left(\mathrm{T}_{1 / 2}\right)$ of total mercury in the brain was significantly longer than the $T_{1 / 2}$ for total mercury in the blood, indicating slow mercury elimination from the brain [29].

In our study, higher mercury retention in internal organs other than brain when given in inorganic form, and higher quantities of excreted mercury in urine and in small and large intestine content when given in organic form of mercury, shows higher excretion rate of inorganic form of mercury. On the other hand, higher concentration of mercury given in organic form in whole blood and the brain points to higher toxic potential of organic mercury at this early age. Although the latter results were expected, they also point to much higher absorption rate of organic mercury and easier transport into brain mass [30]. Significant differences between the two mercury-exposed groups in the blood and the brain at all collection time points (Figure 1) confirmed our preliminary observation $[31,32]$ when mercury was measured in only one sampling point and not determined in small and large intestine.

Concentrations of mercury in small and large intestine given as thiomersal, in spite of being lower than those given as inorganic mercury, show significant enteral mercury excretion. Such data in rodents have not been revealed in the literature so far, especially not at this early age. The latter is in line with finding of increased rate of mercury excretion in infants' stool after parenteral administration of thiomersal during intramuscular vaccination, which lead to an assumption that ethylmercury might be excreted through gastrointestinal system [7]. Our finding of high mercury mass fraction in the small and large intestine of pups 

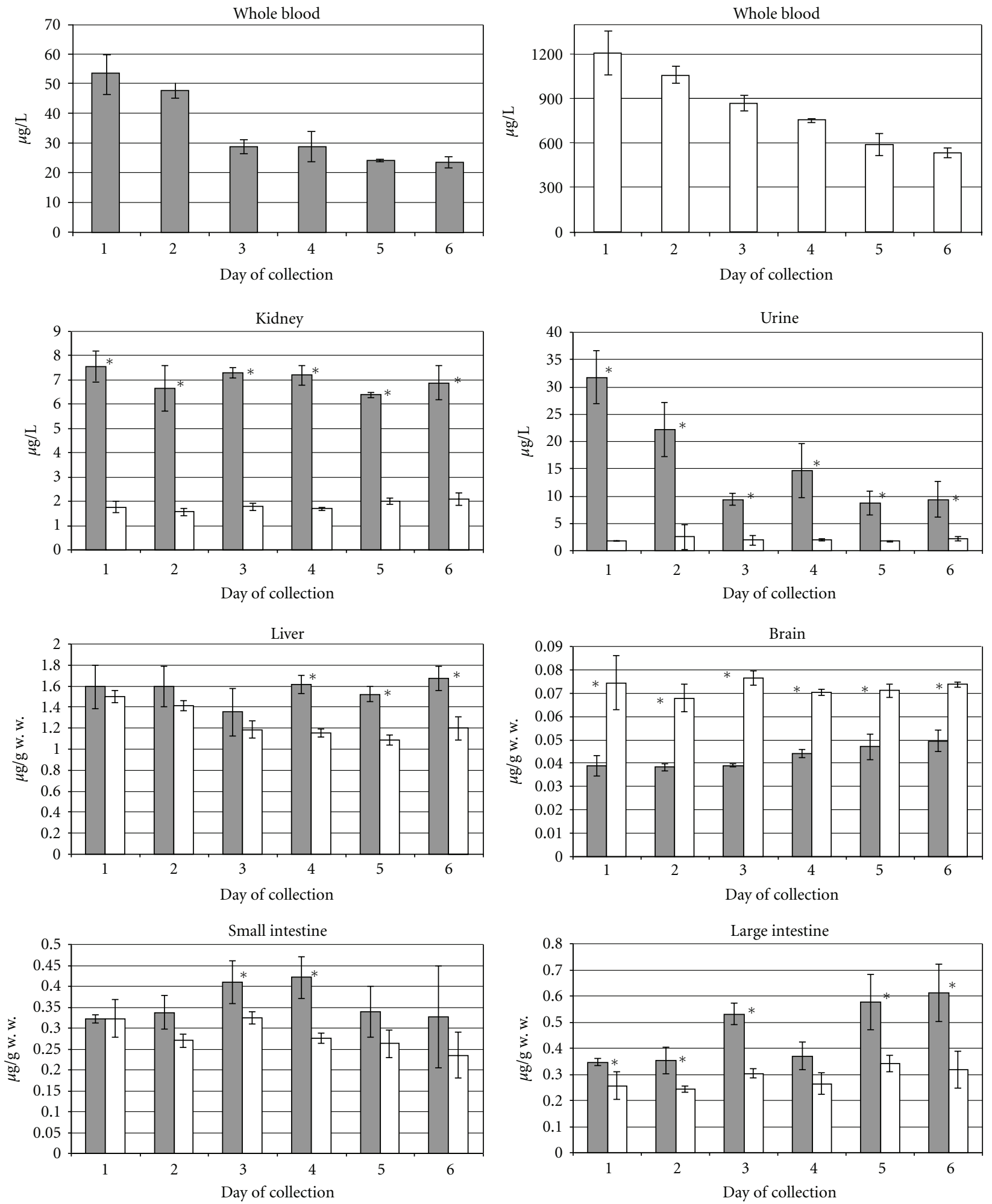

FIGURE 1: Concentrations in whole blood and urine and mass fractions of mercury in organs (kidneys, liver, brain, small intestine, and large intestine) of suckling rats exposed to mercuric chloride $\left(\mathrm{HgCl}_{2}\right.$; grey bars) or thiomersal (ethylmercury; white bars). Data are presented within six days after administration of either form of mercury as means \pm SD; * statistically significant difference between exposed groups (at $P<0.05$ ). 
TABle 2: Descriptive characteristics and Pearson's correlation coefficient between two experimental groups of suckling rats exposed to $\mathrm{HgCl}_{2}$ (mercuric chloride) or thiomersal (ethylmercury). Total mercury was measured in whole blood, urine, and tissues (liver, kidneys, small intestine, large intestine, and brain). Values are presented as $\mu \mathrm{g} / \mathrm{L}$ in whole blood and urine, and as $\mu \mathrm{g} / \mathrm{g}$ w.w. in the liver, kidneys, small intestine, large intestine, and brain.

\begin{tabular}{|c|c|c|c|c|c|c|}
\hline Study group & Samples & Mean & Std. dev. & $N$ & $P$ value & Pearson's $r$ \\
\hline $\mathrm{HgCl}_{2}$ & Whole & 33.2 & 11.0 & 18 & \multirow{2}{*}{0.000} & \multirow{2}{*}{0.899} \\
\hline Thiomersal & blood & 831 & 257 & 18 & & \\
\hline $\mathrm{HgCl}_{2}$ & \multirow{2}{*}{ Urine } & 15.9 & 9.10 & 18 & \multirow{2}{*}{0.742} & \multirow{2}{*}{0.089} \\
\hline Thiomersal & & 2.06 & 0.95 & 18 & & \\
\hline $\mathrm{HgCl}_{2}$ & \multirow{2}{*}{ Liver } & 1546 & 172 & 18 & \multirow{2}{*}{0.77} & \multirow{2}{*}{0.079} \\
\hline Thiomersal & & 1251 & 158 & 18 & & \\
\hline $\mathrm{HgCl}_{2}$ & \multirow{2}{*}{ Kidneys } & 6958 & 589.6 & 18 & \multirow{2}{*}{0.746} & \multirow{2}{*}{-0.088} \\
\hline Thiomersal & & 1818 & 253.5 & 18 & & \\
\hline $\mathrm{HgCl}_{2}$ & \multirow{2}{*}{$\begin{array}{l}\text { Small } \\
\text { intestine }\end{array}$} & 369.9 & 70.76 & 18 & \multirow{2}{*}{0.51} & \multirow{2}{*}{0.178} \\
\hline Thiomersal & & 276.9 & 42.43 & 18 & & \\
\hline $\mathrm{HgCl}_{2}$ & \multirow{2}{*}{$\begin{array}{l}\text { Large } \\
\text { intestine }\end{array}$} & 471.7 & 134.4 & 18 & \multirow{2}{*}{0.026} & \multirow{2}{*}{0.554} \\
\hline Thiomersal & & 284.5 & 48.72 & 18 & & \\
\hline $\mathrm{HgCl}_{2}$ & \multirow{2}{*}{ Brain } & 42.7 & 5.69 & 18 & \multirow{2}{*}{0.444} & \multirow{2}{*}{0.206} \\
\hline Thiomersal & & 72.0 & 5.48 & 18 & & \\
\hline
\end{tabular}

$N=$ Number of rats.

proves that endogenous faecal excretion given in the form of ethylmercury or thiomersal is an important route of excretion and it is probably more important than urinary excretion. This observation was supported by the findings of about three times lower mercury in the kidney and ten times lower mercury in urine of thiomersal-exposed compared to inorganic mercury-exposed pups.

The parallel downward disappearance of mercury from blood is shown by very high correlation between these two mercury forms given to animals (Table 2). Other tissues were either constantly high (kidneys, liver, brain) or even with tendency of increasing (small and large intestine) during the six-day sampling period. Correlations between mercury retention in two experimental groups in other tissues, apart from blood, were mostly not significant except in large intestine where a weak significant correlation was found (Table 2). Such different disposition may be due to easier transport of organic mercury through cell membranes and to partial transformation of organic mercury form during metabolic pathways into inorganic mercury form. It was reported that a high percentage of total mercury in the brain was in the form of inorganic mercury for the thiomersalexposed infant monkeys [29]. The latter also means that after entering into brain, a substantial part of ethylmercury is transformed into inorganic form. Rodrigues and coworkers [30] recently found by speciation analysis that 48 hours after oral thiomersal administration to adult rats the predominant form of mercury in blood was inorganic. In the brain and in other organs, inorganic mercury was predominant as well. There are, however, no speciation data in the literature about the fate of ethylmercury in the brain and other organs given to very young and undeveloped mammals.

In conclusion, although analytical methods that we used did not allow discerning between different mercury species, our experimental design showed that parenterally administered mercury in the form of thiomersal during the suckling period underwent different distribution, retention, and elimination compared to inorganic mercury given under same experimental conditions. In the case of thiomersal exposure, mercury retention is evidently higher in the brain, its urinary excretion is much lower, and enteral excretion is similar to that of inorganic mercury. Our results contribute to the evidence on mercury disposition in the early period of life, comparing in a simple original experimental design the distribution and retention in the brain and other tissues, and elimination of two types of mercury: thiomersal and mercuric chloride mercury. Both mercury forms are present in real life, including the most vulnerable period of growth and development. Our findings are in line with the overall conclusion reached so far in the research initiatives in this area that more work is still needed to elucidate especially neurodevelopmental toxic potential of various forms of mercury and their fate in body in the earliest period of human life.

\section{Acknowledgments}

The experimental results presented in this paper are based on a long-standing research work of Professor Krista Kostial and several generations of her coworkers in the area of mercury toxicology. This work has provided a considerable contribution to the evidence that all forms of mercury are more toxic when administered to infant than adult mammals by showing that under same exposure conditions higher mercury retention is found in the gut and the brain of young compared to adult experimental animals. Our new investigation presented in this paper was supported by the Ministry of Science Education and Sports of the Republic of 
Croatia within approved National Research Project (Grant no. 022-0222148-2135). The technical assistance of Mrs. Đurđa Breški and Mrs. Marija Ciganović is gratefully acknowledged.

\section{References}

[1] T. W. Clarkson, "The three modern faces of mercury," Environmental Health Perspectives, vol. 110, no. 1, pp. 11-23, 2002.

[2] World Health Organisation, Exposure to Mercury: A Major Public Health Concern, WHO Document Production Services, Geneva, Switzerland, 2007.

[3] R. Ramon, M. Murcia, X. Aguinagalde et al., "Prenatal mercury exposure in a multicenter cohort study in Spain," Environment International, vol. 37, no. 3, pp. 597-604, 2011.

[4] L. Magos, "Review on the toxicity of ethylmercury including its presence as a preservative in biological and pharmaceutical products," Journal of Applied Toxicology, vol. 21, no. 1, pp. 1-5, 2001.

[5] L. Magos, "Neurotoxic character of thimerosal and the allometric extrapolation of adult clearance half-time to infants," Journal of Applied Toxicology, vol. 23, no. 4, pp. 263-269, 2003.

[6] S. K. Parker, B. Schwartz, J. Todd, and L. K. Pickering, "Thimerosal-containing vaccines and autistic spectrum disorder: a critical review of published original data," Pediatrics, vol. 114, no. 3, pp. 793-804, 2004.

[7] M. E. Pichichero, A. Gentile, N. Giglio et al., "Mercury levels in premature and low birth weight newborn infants after receipt of thimerosal-containing vaccines," Journal of Pediatrics, vol. 155, no. 4, pp. 495-499, 2009.

[8] D. Rice and S. Barone Jr., "Critical periods of vulnerability for the developing nervous system: evidence from humans and animal models," Environmental Health Perspectives, vol. 108, supplement 3, pp. 511-533, 2000.

[9] L. K. Ball, R. Ball, and R. D. Pratt, "An assessment of thimerosal use in childhood vaccines," Pediatrics, vol. 107, no. 5, pp. 1147-1154, 2001.

[10] N. Andrews, E. Miller, A. Grant, J. Stowe, V. Osborne, and B. Taylor, "Thimerosal exposure in infants and developmental disorders: a retrospective cohort study in the United Kingdom does not support a causal association," Pediatrics, vol. 114, no. 3, pp. 584-591, 2004.

[11] C. J. Clements, "The evidence for the safety of thiomersal in newborn and infant vaccines," Vaccine, vol. 22, no. 15-16, pp. 1854-1861, 2004.

[12] J. D. Clemens and L. Jodar, "Translational research to assist policy decisions about introducing new vaccines in developing countries," Journal of Health, Population and Nutrition, vol. 22, no. 3, pp. 223-231, 2004.

[13] J. Heron, J. Golding, and ALSPAC Study Team, "Thimerosal exposure in infants and developmental disorders: a prospective cohort study in the United Kingdom does not support a causal association," Pediatrics, vol. 114, no. 3, pp. 577-583, 2004.

[14] P. Grandjean and P. Landrigan, "Developmental neurotoxicity of industrial chemicals," The Lancet, vol. 368, no. 9553, pp. 2167-2178, 2006.

[15] J. G. Dórea, "Making sense of epidemiological studies of young children exposed to thimerosal in vaccines," Clinica Chimica Acta, vol. 411, no. 21-22, pp. 1580-1586, 2010.

[16] CIDRAP (Center for Infectious Disease Research and Policy), http://www.cidrap.umn.edu/cidrap/content/other/news/feb0210scan.html, 2010.
[17] The Editors of The Lancet, "Retraction-Ileal-lymphoid-nodular hyperplasia, non-specific colitis, and pervasive developmental disorder in children," [Retraction of A. J. Wakefield, S. H. Murch, A. Anthony etal., The Lancet, vol. 351, no. 9103, pp. 637-641, 1998], The Lancet, vol. 3475, no. 9713, p. 445, 2010.

[18] H. L. Evans, "Cognitive complications of mercury exposure," in Cognitive and Behavioral Abnormalities of Pediatric Diseases, R. D. Nass and Y. French, Eds., pp. 617-619, Oxford University Press, New York, NY, USA, 2010.

[19] S. T. Schultz, "Does thimerosal or other mercury exposure increase the risk for autism? A review of current literature," Acta Neurobiologiae Experimentalis, vol. 70, no. 2, pp. 187-195, 2010.

[20] J. G. Dórea, "Integrating experimental (in vitro and in vivo) neurotoxicity studies of low-dose thimerosal relevant to vaccines," Neurochemical Research, vol. 36, no. 6, pp. 927-938, 2011.

[21] M. Duszczyk-Budhathoki, M. Olczak, M. Lehner, and M. D. Majewska, "Administration of thimerosal to infant rats increases overflow of glutamate and aspartate in the prefrontal cortex: protective role of dehydroepiandrosterone sulfate," Neurochemical Research, vol. 37, no. 2, pp. 436-447, 2012.

[22] K. Kostial, D. Kello, and S. Jugo, "Influence of age on metal metabolism and toxicity," Environmental Health Perspectives, vol. 25, pp. 81-86, 1978.

[23] K. Kostial, I. Rabar, M. Blanuša, and M. Landeka, "Effect of age on heavy metal absorption," Proceedings of the Nutrition Society, vol. 38, no. 2, pp. 251-256, 1979.

[24] K. Kostial, I. Šimonović, I. Rabar, M. Blanuša, and M. Landeka, "Age and intestinal retention of mercury and cadmium in rats," Environmental Research, vol. 31, no. 1, pp. 111-115, 1983.

[25] K. Kostial, M. Blanuša, T. Maljković et al., "Age and sex influence the metabolism and toxicity of metals," in Trace Elements in Man and Animals-7, B. Momčilović, Ed., pp. 16, Institute for Medical Research and Occupational Health, Zagreb, Croatia, 1991.

[26] L. Prester, D. Jureša, and M. Blanuša, "Decomposition of fish samples for determination of mercury," Arhiv za Higijenu Rada i Toksikologiju, vol. 49, no. 4, pp. 343-348, 1998.

[27] H. M. Boylan, R. C. Richter, H. M. Skip Kingston, and A. Ricotta, "Rapid mercury analysis for the field: method development and application to natural gas utility sites," Water, Air, and Soil Pollution, vol. 127, no. 1-4, pp. 255-270, 2001.

[28] G. J. Harry, M. W. Harris, and L. T. Burka, "Mercury concentrations in brain and kidney following ethylmercury, methylmercury and Thimerosal administration to neonatal mice," Toxicology Letters, vol. 154, no. 3, pp. 183-189, 2004.

[29] T. M. Burbacher, D. D. Shen, N. Liberato, K. S. Grant, E. Cernichiari, and T. Clarkson, "Comparison of blood and brain mercury levels in infant monkeys exposed to methylmercury or vaccines containing thimerosal," Environmental Health Perspectives, vol. 113, no. 8, pp. 1015-1021, 2005.

[30] J. L. Rodrigues, J. M. Serpeloni, B. L. Batista, S. S. Souza, and F. Barbosa, "Identification and distribution of mercury species in rat tissues following administration of thimerosal or methylmercury," Archives of Toxicology, vol. 84, no. 11, pp. 891-896, 2010.

[31] T. Orct, M. Blanuša, M. Lazarus, V. M. Varnai, and K. Kostial, "Comparison of organic and inorganic mercury distribution in suckling rat," Journal of Applied Toxicology, vol. 26, no. 6, pp. 536-539, 2006. 
[32] T. Orct, M. Blanuša, M. Lazarus, V. M. Varnai, and K. Kostial, "Effect of thiomersal and mercuric chloride on mercury distribution in suckling rats," Toxicology Letters, vol. S164, no. 6, pp. S191-S192, 2006. 

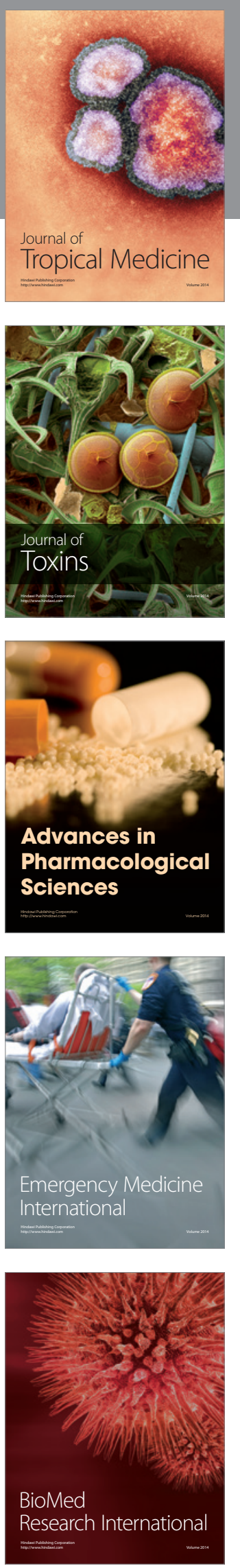
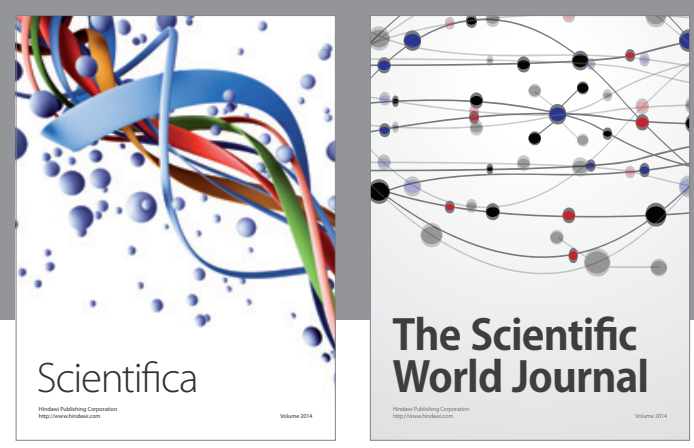

The Scientific World Journal
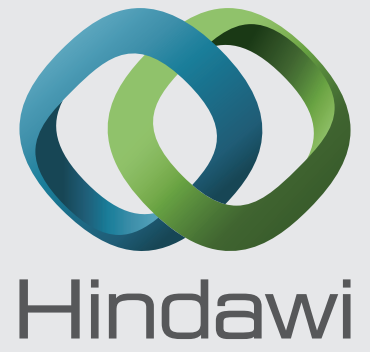

Submit your manuscripts at

http://www.hindawi.com
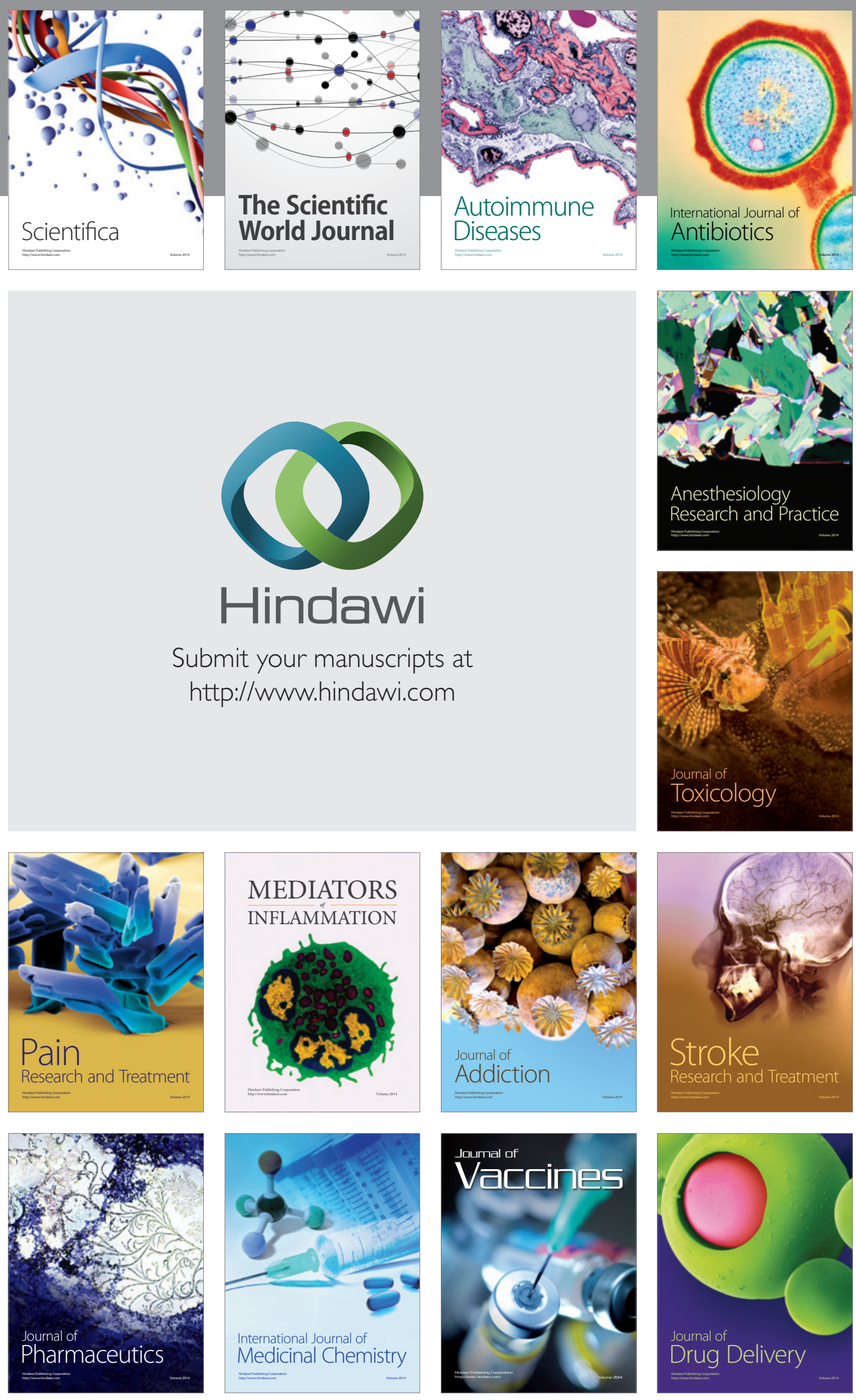